\title{
Generalizations of Steffensen's inequality via some Euler-type identities
}

\author{
Josip Pečarić \\ Faculty of Textile Technology, \\ University of Zagreb, Croatia \\ email: pecaric@element.hr
}

\author{
Anamarija Perušić Pribanić \\ Faculty of Civil Engineering, \\ University of Rijeka, Croatia \\ email: \\ anamarija.perusic@gradri.uniri.hr
}

\author{
Ksenija Smoljak Kalamir \\ Faculty of Textile Technology, \\ University of Zagreb, Croatia \\ email: ksmoljak@ttf.hr
}

\begin{abstract}
Using Euler-type identities some new generalizations of Steffensen's inequality for $n$-convex functions are obtained. Moreover, the Ostrowski-type inequalities related to obtained generalizations are given. Furthermore, using inequalities for the Čebyšev functional in terms of the first derivative some new bounds for the remainder in identities related to generalizations of Steffensen's inequality are proven.
\end{abstract}

\section{Introduction}

Firstly, we recall the well-known Steffensen inequality which reads (see [11]):

Theorem 1 Suppose that $\mathrm{f}$ is nonincreasing and $\mathrm{g}$ is integrable on $[\mathrm{a}, \mathrm{b}]$ with $0 \leq \mathrm{g} \leq 1$ and $\lambda=\int_{\mathrm{a}}^{\mathrm{b}} \mathrm{g}(\mathrm{t}) \mathrm{dt}$. Then we have

$$
\int_{b-\lambda}^{b} f(t) d t \leq \int_{a}^{b} f(t) g(t) d t \leq \int_{a}^{a+\lambda} f(t) d t .
$$

2010 Mathematics Subject Classification: 26D15; 26D20

Key words and phrases: Steffensen's inequality, Euler-type identities, Bernoulli polynomials, Ostrowski-type inequalities, Čebyšev functional 
The inequalities are reversed for $\mathrm{f}$ nondecreasing.

Mitrinović stated in [8] that the inequalities in (1) follow from the identities

$$
\begin{aligned}
& \int_{a}^{a+\lambda} f(t) d t-\int_{a}^{b} f(t) g(t) d t \\
& =\int_{a}^{a+\lambda}[f(t)-f(a+\lambda)][1-g(t)] d t+\int_{a+\lambda}^{b}[f(a+\lambda)-f(t)] g(t) d t
\end{aligned}
$$

and

$$
\begin{aligned}
& \int_{a}^{b} f(t) g(t) d t-\int_{b-\lambda}^{b} f(t) d t \\
& =\int_{a}^{b-\lambda}[f(t)-f(b-\lambda)] g(t) d t+\int_{b-\lambda}^{b}[f(b-\lambda)-f(t)][1-g(t)] d t
\end{aligned}
$$

In [4] Dedić, Matić and Pečarić derived Euler-type identities which extend the well known formula for the expansion of an arbitrary function in Bernoulli polynomials.

Theorem 2 Let $\mathrm{f}:[\mathrm{a}, \mathrm{b}] \rightarrow \mathbb{R}$ be such that $\mathrm{f}^{(\mathrm{n}-1)}$ is continuous function of bounded variation on $[\mathrm{a}, \mathrm{b}]$ for some $\mathrm{n} \geq 1$. Then for every $\mathrm{x} \in[\mathrm{a}, \mathrm{b}]$ we have

$$
f(x)=\frac{1}{b-a} \int_{a}^{b} f(t) d t+T_{n}(x)+R_{n}^{1}(x)
$$

and

$$
f(x)=\frac{1}{b-a} \int_{a}^{b} f(t) d t+T_{n-1}(x)+R_{n}^{2}(x),
$$

where $\mathrm{T}_{0}(\mathrm{x})=0$, and for $1 \leq \mathrm{m} \leq \mathrm{n}$

$$
\begin{aligned}
& T_{m}(x)=\sum_{k=1}^{m} \frac{(b-a)^{k-1}}{k !} B_{k}\left(\frac{x-a}{b-a}\right)\left[f^{(k-1)}(b)-f^{(k-1)}(a)\right], \\
& R_{n}^{1}(x)=-\frac{(b-a)^{n-1}}{n !} \int_{[a, b]} B_{n}^{*}\left(\frac{x-t}{b-a}\right) d f^{(n-1)}(t), \\
& R_{n}^{2}(x)=-\frac{(b-a)^{n-1}}{n !} \int_{[a, b]}\left[B_{n}^{*}\left(\frac{x-t}{b-a}\right)-B_{n}\left(\frac{x-a}{b-a}\right)\right] d f^{(n-1)}(t) .
\end{aligned}
$$


Here, $B_{k}(x), k \geq 0$ are the Bernoulli polynomials, $B_{k}, k \geq 0$ are the Bernoulli numbers and $B_{k}^{*}(x), k \geq 0$ are periodic functions of period one, related to the Bernoulli polynomials as

$$
\mathrm{B}_{\mathrm{k}}^{*}(\mathrm{x})=\mathrm{B}_{\mathrm{k}}(\mathrm{x}), \quad 0 \leq x<1
$$

and

$$
\mathrm{B}_{\mathrm{k}}^{*}(x+1)=\mathrm{B}_{\mathrm{k}}^{*}(x), \quad x \in \mathbb{R} .
$$

Let us recall some properties of the Bernoulli polynomials. The first three Bernoulli polynomials are

$$
\mathrm{B}_{0}(\mathrm{x})=1, \quad \mathrm{~B}_{1}(\mathrm{x})=x-\frac{1}{2}, \quad \mathrm{~B}_{2}(\mathrm{x})=\mathrm{x}^{2}-x+\frac{1}{6},
$$

and

$$
\mathrm{B}_{\mathrm{n}}^{\prime}(x)=\mathrm{nB}_{\mathrm{n}-1}(x), \mathrm{n} \in \mathbb{N} .
$$

$B_{0}^{*}(x)$ is a constant equal to 1 , while $B_{1}^{*}(x)$ is a discontinuous function with a jump of -1 at each integer. For $k \geq 2, B_{k}^{*}(x)$ is a continuous function.

For more details on Bernoulli polynomials and Bernoulli numbers see [1] or [7].

Next, let us recall the definition of the divided difference.

Definition 1 Let $\mathrm{f}$ be a real-valued function defined on the segment $[\mathrm{a}, \mathrm{b}]$. The $\mathrm{n}$-th order divided difference of the function $\mathrm{f}$ at distinct points $x_{0}, \ldots, x_{n} \in$ $[\mathrm{a}, \mathrm{b}]$, is defined recursively by

$$
\left[x_{i} ; f\right]=f\left(x_{i}\right), \quad(i=0, \ldots, n)
$$

and

$$
\left[x_{0}, \ldots, x_{n} ; f\right]=\frac{\left[x_{1}, \ldots, x_{n} ; f\right]-\left[x_{0}, \ldots, x_{n-1} ; f\right]}{x_{n}-x_{0}} .
$$

The value $\left[x_{0}, \ldots, x_{n} ; f\right]$ is independent of the order of the points $x_{0}, \ldots, x_{n}$. The previous definition can be extended to include the case in which some or all of the points coincide by assuming that $x_{0} \leq \cdots \leq x_{n}$ and letting

$$
\underbrace{[x, \ldots, x}_{(j+1) \text { times }} ; f]=\frac{f^{(j)}(x)}{j !},
$$

provided that $\mathrm{f}^{(\mathrm{j})}$ exists. 
In this paper we use Euler-type identities given in Theorem 2 to obtain some new identities related to Steffensen's inequality. Using these new identities we obtain new generalizations of Steffensen's inequality for $n$-convex functions. In Section 3 we give the Ostrowski-type inequalities related to obtained generalizations. In Section 4 we prove some new bounds for the remainder in obtained identities using inequalities for the Cebyšev functional in terms of the first derivative. Further, in Section 5 we give mean value theorems for functionals related to obtained new generalizations of Steffensen's inequality for $n$-convex functions. In Section 6 we use previously defined functionals to construct $n$-exponentially convex functions. We conclude this paper with the applications to Stolarsky-type means.

Throughout the paper, it is assumed that all integrals under consideration exist and that they are finite.

\section{Generalizations of Steffensen's inequality via Euler- type identities}

The aim of this section is to obtain generalizations of Steffensen's inequality for $n$-convex functions using the identities (4) and (5). We begin with the following result:

Theorem 3 Let $\mathrm{f}:[\mathrm{a}, \mathrm{b}] \rightarrow \mathbb{R}$ be such that $\mathrm{f}^{(\mathrm{n}-1)}$ is continuous function of bounded variation on $[\mathrm{a}, \mathrm{b}]$ for some $\mathrm{n} \geq 2$ and let $\mathrm{g}:[\mathrm{a}, \mathrm{b}] \rightarrow \mathbb{R}$ be an integrable function. Let $\lambda=\int_{a}^{b} \mathrm{~g}(\mathrm{t}) \mathrm{dt}$ and let the function $\mathrm{G}_{1}$ be defined by

$$
G_{1}(x)= \begin{cases}\int_{a}^{x}(1-g(t)) d t, & x \in[a, a+\lambda], \\ \int_{x}^{b} g(t) d t, & x \in[a+\lambda, b] .\end{cases}
$$

Then

$$
\begin{aligned}
& \int_{a}^{a+\lambda} f(t) d t-\int_{a}^{b} f(t) g(t) d t \\
& +\sum_{k=1}^{n} \frac{(b-a)^{k-2}}{(k-1) !}\left(\int_{a}^{b} G_{1}(x) B_{k-1}\left(\frac{x-a}{b-a}\right) d x\right) \times\left[f^{(k-1)}(b)-f^{(k-1)}(a)\right] \\
& =\frac{(b-a)^{n-2}}{(n-1) !} \int_{a}^{b}\left(\int_{a}^{b} G_{1}(x) B_{n-1}^{*}\left(\frac{x-t}{b-a}\right) d x\right) f^{(n)}(t) d t .
\end{aligned}
$$


Proof. Applying integration by parts and then using the definition of the function $\mathrm{G}_{1}$, the identity (2) becomes

$$
\begin{aligned}
\int_{a}^{a+\lambda} f(t) d t & -\int_{a}^{b} f(t) g(t) d t \\
& =-\int_{a}^{a+\lambda}\left(\int_{a}^{x}(1-g(t) d t) d f(x)-\int_{a+\lambda}^{b}\left(\int_{x}^{b} g(t) d t\right) d f(x)\right. \\
& =-\int_{a}^{b} G_{1}(x) f^{\prime}(x) d x .
\end{aligned}
$$

Now applying the identity (4) on the function $f^{\prime}$ we obtain

$$
\begin{aligned}
f^{\prime}(x)= & \frac{f(b)-f(a)}{b-a}+\sum_{k=1}^{n} \frac{(b-a)^{k-1}}{k !} B_{k}\left(\frac{x-a}{b-a}\right)\left[f^{(k)}(b)-f^{(k)}(a)\right] \\
& -\frac{(b-a)^{n-1}}{n !} \int_{a}^{b} B_{n}^{*}\left(\frac{x-t}{b-a}\right) f^{(n+1)}(t) d t \\
= & \sum_{k=0}^{n} \frac{(b-a)^{k-1}}{k !} B_{k}\left(\frac{x-a}{b-a}\right)\left[f^{(k)}(b)-f^{(k)}(a)\right] \\
& -\frac{(b-a)^{n-1}}{n !} \int_{a}^{b} B_{n}^{*}\left(\frac{x-t}{b-a}\right) f^{(n+1)}(t) d t .
\end{aligned}
$$

Hence, using (9) we obtain

$$
\begin{aligned}
& \int_{a}^{b} G_{1}(x) f^{\prime}(x) d x \\
& =\sum_{k=0}^{n} \frac{(b-a)^{k-1}}{k !}\left(\int_{a}^{b} G_{1}(x) B_{k}\left(\frac{x-a}{b-a}\right) d x\right)\left[f^{(k)}(b)-f^{(k)}(a)\right] \\
& \quad-\frac{(b-a)^{n-1}}{n !} \int_{a}^{b} G_{1}(x)\left(\int_{a}^{b} B_{n}^{*}\left(\frac{x-t}{b-a}\right) f^{(n+1)}(t) d t\right) d x .
\end{aligned}
$$

Applying Fubini's theorem on the last term in (10) and replacing $n$ with $n-1$ we obtain (8). This identity is valid for $n-1 \geq 1$, i.e. $n \geq 2$.

Similarly, using the identity (5) the following theorem holds.

Theorem 4 Let $\mathrm{f}:[\mathrm{a}, \mathrm{b}] \rightarrow \mathbb{R}$ be such that $\mathrm{f}^{(\mathrm{n}-1)}$ is continuous function of bounded variation on $[\mathrm{a}, \mathrm{b}]$ for some $\mathrm{n} \geq 2$ and let $\mathrm{g}:[\mathrm{a}, \mathrm{b}] \rightarrow \mathbb{R}$ be an 
integrable function. Let $\lambda=\int_{a}^{b} g(t) d t$ and let the function $\mathrm{G}_{1}$ be defined by (7). Then

$$
\begin{aligned}
& \int_{a}^{a+\lambda} f(t) d t-\int_{a}^{b} f(t) g(t) d t \\
& \quad+\sum_{k=1}^{n-1} \frac{(b-a)^{k-2}}{(k-1) !}\left(\int_{a}^{b} G_{1}(x) B_{k-1}\left(\frac{x-a}{b-a}\right) d x\right)\left[f^{(k-1)}(b)-f^{(k-1)}(a)\right] \\
& =\frac{(b-a)^{n-2}}{(n-1) !} \int_{a}^{b}\left(\int_{a}^{b} G_{1}(x)\left[B_{n-1}^{*}\left(\frac{x-t}{b-a}\right)-B_{n-1}\left(\frac{x-a}{b-a}\right)\right] d x\right) f^{(n)}(t) d t .
\end{aligned}
$$

We continue with the results related to the identity (3).

Theorem 5 Let $\mathrm{f}:[\mathrm{a}, \mathrm{b}] \rightarrow \mathbb{R}$ be such that $\mathrm{f}^{(\mathrm{n}-1)}$ is continuous function of bounded variation on $[\mathrm{a}, \mathrm{b}]$ for some $\mathrm{n} \geq 2$ and let $\mathrm{g}:[\mathrm{a}, \mathrm{b}] \rightarrow \mathbb{R}$ be an integrable function. Let $\lambda=\int_{a}^{b} \mathrm{~g}(\mathrm{t}) \mathrm{dt}$ and let the function $\mathrm{G}_{2}$ be defined by

$$
G_{2}(x)= \begin{cases}\int_{a}^{x} g(t) d t, & x \in[a, b-\lambda], \\ \int_{x}^{b}(1-g(t)) d t, & x \in[b-\lambda, b] .\end{cases}
$$

Then

$$
\begin{aligned}
& \int_{a}^{b} f(t) g(t) d t-\int_{b-\lambda}^{b} f(t) d t \\
& \quad+\sum_{k=1}^{n} \frac{(b-a)^{k-2}}{(k-1) !}\left(\int_{a}^{b} G_{2}(x) B_{k-1}\left(\frac{x-a}{b-a}\right) d x\right) \times\left[f^{(k-1)}(b)-f^{(k-1)}(a)\right] \\
& =\frac{(b-a)^{n-2}}{(n-1) !} \int_{a}^{b}\left(\int_{a}^{b} G_{2}(x) B_{n-1}^{*}\left(\frac{x-t}{b-a}\right) d x\right) f^{(n)}(t) d t .
\end{aligned}
$$

Proof. Similar to the proof of Theorem 3 applying integration by parts on the identity (3) and then using the identity (4) on the function $f^{\prime}$.

Theorem 6 Let $\mathrm{f}:[\mathrm{a}, \mathrm{b}] \rightarrow \mathbb{R}$ be such that $\mathrm{f}^{(\mathrm{n}-1)}$ is continuous function of bounded variation on $[\mathrm{a}, \mathrm{b}]$ for some $\mathrm{n} \geq 2$ and let $\mathrm{g}:[\mathrm{a}, \mathrm{b}] \rightarrow \mathbb{R}$ be an integrable function. Let $\lambda=\int_{a}^{b} \mathrm{~g}(\mathrm{t}) \mathrm{dt}$ and let the function $\mathrm{G}_{2}$ be defined by 
(12). Then

$$
\begin{aligned}
& \int_{a}^{b} f(t) g(t) d t-\int_{b-\lambda}^{b} f(t) d t \\
& \quad+\sum_{k=1}^{n-1} \frac{(b-a)^{k-2}}{(k-1) !}\left(\int_{a}^{b} G_{2}(x) B_{k-1}\left(\frac{x-a}{b-a}\right) d x\right)\left[f^{(k-1)}(b)-f^{(k-1)}(a)\right] \\
& =\frac{(b-a)^{n-2}}{(n-1) !} \int_{a}^{b}\left(\int_{a}^{b} G_{2}(x)\left[B_{n-1}^{*}\left(\frac{x-t}{b-a}\right)-B_{n-1}\left(\frac{x-a}{b-a}\right)\right] d x\right) f^{(n)}(t) d t .
\end{aligned}
$$

Proof. Similar to the proof of Theorem 5 using the identity (5) on the function $f^{\prime}$.

Using previously obtained identities we can obtain the following generalizations of Steffensen's inequality for $n$-convex functions.

Theorem 7 Let $\mathrm{f}:[\mathrm{a}, \mathrm{b}] \rightarrow \mathbb{R}$ be such that $\mathrm{f}^{(\mathrm{n}-1)}$ is continuous function of bounded variation on $[\mathrm{a}, \mathrm{b}]$ for some $\mathrm{n} \geq 2$ and let $\mathrm{g}:[\mathrm{a}, \mathrm{b}] \rightarrow \mathbb{R}$ be an integrable function. Let $\lambda=\int_{a}^{b} \mathrm{~g}(\mathrm{t}) \mathrm{dt}$ and let the function $\mathrm{G}_{1}$ be defined by (7).

(i) If $\mathrm{f}$ is $\mathrm{n}$-convex and

$$
\int_{a}^{b} G_{1}(x) B_{n-1}^{*}\left(\frac{x-t}{b-a}\right) d x \geq 0, \quad t \in[a, b],
$$

then

$$
\begin{aligned}
& \int_{a}^{b} f(t) g(t) d t \leq \int_{a}^{a+\lambda} f(t) d t \\
& +\sum_{k=1}^{n} \frac{(b-a)^{k-2}}{(k-1) !}\left(\int_{a}^{b} G_{1}(x) B_{k-1}\left(\frac{x-a}{b-a}\right) d x\right)\left[f^{(k-1)}(b)-f^{(k-1)}(a)\right] .
\end{aligned}
$$

(ii) If $\mathrm{f}$ is $\mathrm{n}$-convex and

$$
\begin{aligned}
& \quad \int_{a}^{b} G_{1}(x)\left[B_{n-1}^{*}\left(\frac{x-t}{b-a}\right)-B_{n-1}\left(\frac{x-a}{b-a}\right)\right] d x \geq 0, \quad t \in[a, b], \\
& \text { then } \\
& \int_{a}^{b} f(t) g(t) d t \leq \int_{a}^{a+\lambda} f(t) d t \\
& +\sum_{k=1}^{n-1} \frac{(b-a)^{k-2}}{(k-1) !}\left(\int_{a}^{b} G_{1}(x) B_{k-1}\left(\frac{x-a}{b-a}\right) d x\right)\left[f^{(k-1)}(b)-f^{(k-1)}(a)\right] .
\end{aligned}
$$


Proof. If the function $f$ is $n$-convex, without loss of generality we can assume that $f$ is $n$-times differentiable and $f^{(\mathfrak{n})} \geq 0$ see $[10$, p. 16 and p. 293]. Now we can apply Theorem 3 to obtain (16) and Theorem 4 to obtain (18).

Similarly, applying Theorems 5 and 6 we obtain the following generalizations of Steffensen's inequality for $n-$ convex functions.

Theorem 8 Let $\mathrm{f}:[\mathrm{a}, \mathrm{b}] \rightarrow \mathbb{R}$ be such that $\mathrm{f}^{(\mathrm{n}-1)}$ is continuous function of bounded variation on $[\mathrm{a}, \mathrm{b}]$ for some $\mathrm{n} \geq 2$ and let $\mathrm{g}:[\mathrm{a}, \mathrm{b}] \rightarrow \mathbb{R}$ be an integrable function. Let $\lambda=\int_{\mathrm{a}}^{\mathrm{b}} \mathrm{g}(\mathrm{t}) \mathrm{dt}$ and let the function $\mathrm{G}_{2}$ be defined by (12).

(i) If $\mathrm{f}$ is $\mathrm{n}$-convex and

$$
\int_{a}^{b} G_{2}(x) B_{n-1}^{*}\left(\frac{x-t}{b-a}\right) d x \geq 0, \quad t \in[a, b],
$$

then

$$
\begin{aligned}
& \int_{a}^{b} f(t) g(t) d t \geq \int_{b-\lambda}^{b} f(t) d t \\
& -\sum_{k=1}^{n} \frac{(b-a)^{k-2}}{(k-1) !}\left(\int_{a}^{b} G_{2}(x) B_{k-1}\left(\frac{x-a}{b-a}\right) d x\right)\left[f^{(k-1)}(b)-f^{(k-1)}(a)\right] .
\end{aligned}
$$

(ii) If $\mathrm{f}$ is $\mathrm{n}$-convex and

$$
\int_{a}^{b} G_{2}(x)\left[B_{n-1}^{*}\left(\frac{x-t}{b-a}\right)-B_{n-1}\left(\frac{x-a}{b-a}\right)\right] d x \geq 0, \quad t \in[a, b],
$$

then

$$
\begin{aligned}
& \int_{a}^{b} f(t) g(t) d t \geq \int_{b-\lambda}^{b} f(t) d t \\
& -\sum_{k=1}^{n-1} \frac{(b-a)^{k-2}}{(k-1) !}\left(\int_{a}^{b} G_{2}(x) B_{k-1}\left(\frac{x-a}{b-a}\right) d x\right)\left[f^{(k-1)}(b)-f^{(k-1)}(a)\right] .
\end{aligned}
$$

\section{Ostrowski-type inequalities}

In this section we give the Ostrowski-type inequalities related to generalizations obtained in the previous section. 
Theorem 9 Suppose that all assumptions of Theorem 3 hold. Assume (p, q) is a pair of conjugate exponents, that is $1 \leq p, q \leq \infty, 1 / p+1 / q=1$. Let $\left|\mathrm{f}^{(\mathrm{n})}\right|^{\mathrm{p}}:[\mathrm{a}, \mathrm{b}] \rightarrow \mathbb{R}$ be an $R$-integrable function for some $\mathrm{n} \geq 2$. Then we have

$$
\begin{aligned}
& \mid \int_{a}^{a+\lambda} f(t) d t-\int_{a}^{b} f(t) g(t) d t \\
& +\sum_{k=1}^{n} \frac{(b-a)^{k-2}}{(k-1) !}\left(\int_{a}^{b} G_{1}(x) B_{k-1}\left(\frac{x-a}{b-a}\right) d x\right)\left[f^{(k-1)}(b)-f^{(k-1)}(a)\right] \mid \\
& \leq \frac{(b-a)^{n-2}}{(n-1) !}\left\|f^{(n)}\right\|_{p}\left(\int_{a}^{b}\left|\int_{a}^{b} G_{1}(x) B_{n-1}^{*}\left(\frac{x-t}{b-a}\right) d x\right|^{q} d t\right)^{\frac{1}{q}} .
\end{aligned}
$$

The constant on the right-hand side of (23) is sharp for $1<p \leq \infty$ and the best possible for $\mathrm{p}=1$.

Proof. Let us denote

$$
C(t)=\frac{(b-a)^{n-2}}{(n-1) !} \int_{a}^{b} G_{1}(x) B_{n-1}^{*}\left(\frac{x-t}{b-a}\right) d x .
$$

Using the identity (8) and applying Hölder's inequality we obtain

$$
\begin{aligned}
& \mid \int_{a}^{a+\lambda} f(t) d t-\int_{a}^{b} f(t) g(t) d t \\
& +\sum_{k=1}^{n} \frac{(b-a)^{k-2}}{(k-1) !}\left(\int_{a}^{b} G_{1}(x) B_{k-1}\left(\frac{x-a}{b-a}\right) d x\right)\left[f^{(k-1)}(b)-f^{(k-1)}(a)\right] \mid \\
& =\left|\int_{a}^{b} C(t) f^{(n)}(t) d t\right| \leq\left\|f^{(n)}\right\|_{p}\left(\int_{a}^{b}|C(t)|^{q} d t\right)^{\frac{1}{q}} .
\end{aligned}
$$

For the proof of the sharpness of the constant $\left(\int_{a}^{b}|C(t)|^{q} d t\right)^{\frac{1}{q}}$ let us find a function $f$ for which the equality in $(23)$ is obtained.

For $1<p<\infty$ take $f$ to be such that

$$
f^{(n)}(t)=\operatorname{sgn} C(t)|C(t)|^{\frac{1}{p-1}} .
$$

For $p=\infty$ take $f^{(n)}(t)=\operatorname{sgn} C(t)$.

For $p=1$ we prove that

$$
\left|\int_{a}^{b} C(t) f^{(n)}(t) d t\right| \leq \max _{t \in[a, b]}|C(t)|\left(\int_{a}^{b}\left|f^{(n)}(t)\right| d t\right)
$$


is the best possible inequality. Suppose that $|\mathrm{C}(\mathrm{t})|$ attains its maximum at $t_{0} \in[a, b]$. First we assume that $C\left(t_{0}\right)>0$. For $\varepsilon$ small enough we define $f_{\varepsilon}(t)$ by

$$
f_{\varepsilon}(t)= \begin{cases}0, & a \leq t \leq t_{0} \\ \frac{1}{\varepsilon n !}\left(t-t_{0}\right)^{n}, & t_{0} \leq t \leq t_{0}+\varepsilon \\ \frac{1}{n !}\left(t-t_{0}\right)^{n-1}, & t_{0}+\varepsilon \leq t \leq b\end{cases}
$$

Then for $\varepsilon$ small enough

$$
\left|\int_{a}^{b} C(t) f^{(n)}(t) d t\right|=\left|\int_{t_{0}}^{t_{0}+\varepsilon} C(t) \frac{1}{\varepsilon} d t\right|=\frac{1}{\varepsilon} \int_{t_{0}}^{t_{0}+\varepsilon} C(t) d t .
$$

Now from the inequality (24) we have

$$
\frac{1}{\varepsilon} \int_{t_{0}}^{t_{0}+\varepsilon} C(t) d t \leq C\left(t_{0}\right) \int_{t_{0}}^{t_{0}+\varepsilon} \frac{1}{\varepsilon} d t=C\left(t_{0}\right) .
$$

Since,

$$
\lim _{\varepsilon \rightarrow 0} \frac{1}{\varepsilon} \int_{t_{0}}^{t_{0}+\varepsilon} C(t) d t=C\left(t_{0}\right)
$$

the statement follows. In the case $C\left(t_{0}\right)<0$, we define $f_{\varepsilon}(t)$ by

$$
f_{\varepsilon}(t)= \begin{cases}\frac{1}{n !}\left(t-t_{0}-\varepsilon\right)^{n-1},, & a \leq t \leq t_{0} \\ -\frac{1}{\varepsilon n !}\left(t-t_{0}-\varepsilon\right)^{n}, & t_{0} \leq t \leq t_{0}+\varepsilon \\ 0, & t_{0}+\varepsilon \leq t \leq b\end{cases}
$$

and the rest of the proof is the same as above.

Using the identity (11) we obtain the following result.

Theorem 10 Suppose that all assumptions of Theorem 4 hold. Assume (p, q) is a pair of conjugate exponents, that is $1 \leq \mathrm{p}, \mathrm{q} \leq \infty, 1 / \mathrm{p}+1 / \mathrm{q}=1$. Let $\left|f^{(n)}\right|^{p}:[a, b] \rightarrow \mathbb{R}$ be an R-integrable function for some $\mathrm{n} \geq 2$. Then we have

$$
\begin{aligned}
& \mid \int_{a}^{a+\lambda} f(t) d t-\int_{a}^{b} f(t) g(t) d t \\
& \quad+\sum_{k=1}^{n-1} \frac{(b-a)^{k-2}}{(k-1) !}\left(\int_{a}^{b} G_{1}(x) B_{k-1}\left(\frac{x-a}{b-a}\right) d x\right)\left[f^{(k-1)}(b)-f^{(k-1)}(a)\right] \mid \\
& \leq \frac{(b-a)^{n-2}}{(n-1) !}\left\|f^{(n)}\right\|_{p}\left(\int_{a}^{b} \mid \int_{a}^{b} G_{1}(x)\left[B_{n-1}^{*}\left(\frac{x-t}{b-a}\right)\right.\right. \\
& \left.\left.\quad-B_{n-1}\left(\frac{x-a}{b-a}\right)\right]\left.d x\right|^{q} d t\right)^{\frac{1}{q}} .
\end{aligned}
$$


The constant on the right-hand side of (25) is sharp for $1<p \leq \infty$ and the best possible for $\mathrm{p}=1$.

Similarly, we obtain the following Ostrowski-type inequalities related to results given in Theorems 5 and 6 .

Theorem 11 Suppose that all assumptions of Theorem 5 hold. Assume $(\mathrm{p}, \mathrm{q})$ is a pair of conjugate exponents, that is $1 \leq \mathrm{p}, \mathrm{q} \leq \infty, 1 / \mathrm{p}+1 / \mathrm{q}=1$. Let $\left|\mathrm{f}^{(\mathrm{n})}\right|^{p}:[\mathrm{a}, \mathrm{b}] \rightarrow \mathbb{R}$ be an $R$-integrable function for some $\mathrm{n} \geq 2$. Then we have

$$
\begin{aligned}
& \mid \int_{a}^{b} f(t) g(t) d t-\int_{b-\lambda}^{b} f(t) d t \\
& +\sum_{k=1}^{n} \frac{(b-a)^{k-2}}{(k-1) !}\left(\int_{a}^{b} G_{2}(x) B_{k-1}\left(\frac{x-a}{b-a}\right) d x\right)\left[f^{(k-1)}(b)-f^{(k-1)}(a)\right] \mid \\
& \leq \frac{(b-a)^{n-2}}{(n-1) !}\left\|f^{(n)}\right\|_{p}\left(\int_{a}^{b}\left|\int_{a}^{b} G_{2}(x) B_{n-1}^{*}\left(\frac{x-t}{b-a}\right) d x\right|^{q} d t\right)^{\frac{1}{q}} .
\end{aligned}
$$

The constant on the right-hand side of (26) is sharp for $1<p \leq \infty$ and the best possible for $\mathrm{p}=1$.

Theorem 12 Suppose that all assumptions of Theorem 6 hold. Assume (p, q) is a pair of conjugate exponents, that is $1 \leq p, q \leq \infty, 1 / p+1 / q=1$. Let $\left|\mathrm{f}^{(\mathrm{n})}\right|^{\mathrm{p}}:[\mathrm{a}, \mathrm{b}] \rightarrow \mathbb{R}$ be an $R$-integrable function for some $\mathrm{n} \geq 2$. Then we have

$$
\begin{aligned}
& \mid \int_{a}^{b} f(t) g(t) d t-\int_{b-\lambda}^{b} f(t) d t \\
& \quad+\sum_{k=1}^{n-1} \frac{(b-a)^{k-2}}{(k-1) !}\left(\int_{a}^{b} G_{2}(x) B_{k-1}\left(\frac{x-a}{b-a}\right) d x\right)\left[f^{(k-1)}(b)-f^{(k-1)}(a)\right] \mid \\
& \leq \frac{(b-a)^{n-2}}{(n-1) !}\left\|f^{(n)}\right\|_{p}\left(\int_{a}^{b} \mid \int_{a}^{b} G_{2}(x)\left[B_{n-1}^{*}\left(\frac{x-t}{b-a}\right)\right.\right. \\
& \left.\left.\quad-B_{n-1}\left(\frac{x-a}{b-a}\right)\right]\left.d x\right|^{q} d t\right)^{\frac{1}{q}} .
\end{aligned}
$$

The constant on the right-hand side of (27) is sharp for $1<p \leq \infty$ and the best possible for $\mathrm{p}=1$. 


\section{Generalizations related to the bounds for the Čebyšev functional}

Let $f, h:[a, b] \rightarrow \mathbb{R}$ be two Lebesgue integrable functions. By $T(f, h)$ we denote the Čebyšev functional

$$
T(f, h):=\frac{1}{b-a} \int_{a}^{b} f(t) h(t) d t-\frac{1}{b-a} \int_{a}^{b} f(t) d t \cdot \frac{1}{b-a} \int_{a}^{b} h(t) d t .
$$

In [3] Cerone and Dragomir proved the following bound for the Čebyšev functional.

Theorem 13 Let $\mathrm{f}:[\mathrm{a}, \mathrm{b}] \rightarrow \mathbb{R}$ be a Lebesgue integrable function and $\mathrm{h}:$ $[\mathrm{a}, \mathrm{b}] \rightarrow \mathbb{R}$ be an absolutely continuous function with $(\cdot-\mathrm{a})(\mathrm{b}-\cdot)\left[\mathrm{h}^{\prime}\right]^{2} \in \mathrm{L}[\mathrm{a}, \mathrm{b}]$. Then we have the inequality

$$
|T(f, h)| \leq \frac{1}{\sqrt{2}}[T(f, f)]^{\frac{1}{2}} \frac{1}{\sqrt{b-a}}\left(\int_{a}^{b}(x-a)(b-x)\left[h^{\prime}(x)\right]^{2} d x\right)^{\frac{1}{2}} .
$$

The constant $\frac{1}{\sqrt{2}}$ in (28) is the best possible.

Also, Cerone and Dragomir [3] proved the following inequality of Grüss type.

Theorem 14 Assume that $\mathrm{h}:[\mathrm{a}, \mathrm{b}] \rightarrow \mathbb{R}$ is monotonic nondecreasing on $[\mathrm{a}, \mathrm{b}]$ and $\mathrm{f}:[\mathrm{a}, \mathrm{b}] \rightarrow \mathbb{R}$ is absolutely continuous with $\mathrm{f}^{\prime} \in \mathrm{L}_{\infty}[\mathrm{a}, \mathrm{b}]$. Then we have the inequality

$$
|T(f, h)| \leq \frac{1}{2(b-a)}\left\|f^{\prime}\right\|_{\infty} \int_{a}^{b}(x-a)(b-x) \operatorname{dh}(x) .
$$

The constant $\frac{1}{2}$ in (29) is the best possible.

In the sequel we use the aforementioned bound for the Čebyšev functional to obtain generalizations of the results proved in Section 2.

Firstly, let us denote

$$
H_{1}(t)=\int_{a}^{b} G_{1}(x) B_{n-1}^{*}\left(\frac{x-t}{b-a}\right) d x
$$


Theorem 15 Let $\mathrm{f}:[\mathrm{a}, \mathrm{b}] \rightarrow \mathbb{R}$ be such that $\mathrm{f}^{(\mathrm{n})}$ is absolutely continuous function for some $\mathrm{n} \geq 2$ with $(\cdot-\mathrm{a})(\mathrm{b}-\cdot)\left[\mathrm{f}^{(\mathrm{n}+1)}\right]^{2} \in \mathrm{L}[\mathrm{a}, \mathrm{b}]$ and let $\mathrm{g}$ be an integrable function on $[\mathrm{a}, \mathrm{b}]$. Let $\lambda=\int_{\mathrm{a}}^{\mathrm{b}} \mathrm{g}(\mathrm{t}) \mathrm{dt}$ and let the functions $\mathrm{G}_{1}$ and $\mathrm{H}_{1}$ be defined by (7) and (30). Then

$$
\begin{aligned}
& \int_{a}^{a+\lambda} f(t) d t-\int_{a}^{b} f(t) g(t) d t \\
& +\sum_{k=1}^{n} \frac{(b-a)^{k-2}}{(k-1) !}\left(\int_{a}^{b} G_{1}(x) B_{k-1}\left(\frac{x-a}{b-a}\right) d x\right)\left[f^{(k-1)}(b)-f^{(k-1)}(a)\right] \\
& -\frac{(b-a)^{n-3}\left[f^{(n-1)}(b)-f^{(n-1)}(a)\right]}{(n-1) !} \int_{a}^{b} H_{1}(t) d t=S_{n}^{1}(f ; a, b)
\end{aligned}
$$

where the remainder $S_{\mathfrak{n}}^{1}(f ; a, b)$ satisfies the estimation

$$
\left|S_{n}^{1}(f ; a, b)\right| \leq \frac{(b-a)^{n-\frac{3}{2}}}{\sqrt{2}(n-1) !}\left[T\left(H_{1}, H_{1}\right)\right]^{\frac{1}{2}}\left|\int_{a}^{b}(t-a)(b-t)\left[f^{(n+1)}(t)\right]^{2} d t\right|^{\frac{1}{2}} .
$$

Proof. Applying Theorem 13 for $\mathrm{f} \rightarrow \mathrm{H}_{1}$ and $\mathrm{h} \rightarrow \mathrm{f}^{(\mathrm{n})}$ we obtain

$$
\begin{aligned}
& \left|\frac{1}{b-a} \int_{a}^{b} H_{1}(t) f^{(n)}(t) d t-\frac{1}{b-a} \int_{a}^{b} H_{1}(t) d t \cdot \frac{1}{b-a} \int_{a}^{b} f^{(n)}(t) d t\right| \\
& \leq \frac{1}{\sqrt{2}}\left[T\left(H_{1}, H_{1}\right)\right]^{\frac{1}{2}} \frac{1}{\sqrt{b-a}}\left|\int_{a}^{b}(t-a)(b-t)\left[f^{(n+1)}(t)\right]^{2} d t\right|^{\frac{1}{2}} .
\end{aligned}
$$

Hence, if we subtract

$$
\begin{aligned}
\frac{(b-a)^{n-1}}{(n-1) !} \cdot \frac{1}{b-a} & \int_{a}^{b} H_{1}(t) d t \cdot \frac{1}{b-a} \int_{a}^{b} f^{(n)}(t) d t \\
& =\frac{(b-a)^{n-3}}{(n-1) !}\left[f^{(n-1)}(b)-f^{(n-1)}(a)\right] \int_{a}^{b} H_{1}(t) d t
\end{aligned}
$$

from both side of the identity (8) and use the inequality (33) we obtain the representation (31).

Similarly, using the identity (11) we obtain the following result. Let us denote

$$
\Phi_{1}(t)=\int_{a}^{b} G_{1}(x)\left[B_{n-1}^{*}\left(\frac{x-t}{b-a}\right)-B_{n-1}\left(\frac{x-a}{b-a}\right)\right] d x .
$$


Theorem 16 Let $\mathrm{f}:[\mathrm{a}, \mathrm{b}] \rightarrow \mathbb{R}$ be such that $\mathrm{f}^{(\mathrm{n})}$ is absolutely continuous function for some $\mathrm{n} \geq 2$ with $(\cdot-\mathrm{a})(\mathrm{b}-\cdot)\left[\mathrm{f}^{(\mathrm{n}+1)}\right]^{2} \in \mathrm{L}[\mathrm{a}, \mathrm{b}]$ and let $\mathrm{g}$ be an integrable function on $[\mathrm{a}, \mathrm{b}]$. Let $\lambda=\int_{\mathrm{a}}^{\mathrm{b}} \mathrm{g}(\mathrm{t}) \mathrm{dt}$ and let the functions $\mathrm{G}_{1}$ and $\Phi_{1}$ be defined by (7) and (34). Then

$$
\begin{aligned}
& \int_{a}^{a+\lambda} f(t) d t-\int_{a}^{b} f(t) g(t) d t \\
& +\sum_{k=1}^{n-1} \frac{(b-a)^{k-2}}{(k-1) !}\left(\int_{a}^{b} G_{1}(x) B_{k-1}\left(\frac{x-a}{b-a}\right) d x\right)\left[f^{(k-1)}(b)-f^{(k-1)}(a)\right] \\
& -\frac{(b-a)^{n-3}\left[f^{(n-1)}(b)-f^{(n-1)}(a)\right]}{(n-1) !} \int_{a}^{b} \Phi_{1}(t) d t=S_{n}^{2}(f ; a, b)
\end{aligned}
$$

where the remainder $S_{\mathfrak{n}}^{2}(f ; a, b)$ satisfies the estimation

$$
\left|S_{n}^{2}(f ; a, b)\right| \leq \frac{(b-a)^{n-\frac{3}{2}}}{\sqrt{2}(n-1) !}\left[T\left(\Phi_{1}, \Phi_{1}\right)\right]^{\frac{1}{2}}\left|\int_{a}^{b}(t-a)(b-t)\left[f^{(n+1)}(t)\right]^{2} d t\right|^{\frac{1}{2}} .
$$

We continue with the results related to the identities (13) and (14). Let us denote

$$
H_{2}(t)=\int_{a}^{b} G_{2}(x) B_{n-1}^{*}\left(\frac{x-t}{b-a}\right) d x
$$

and

$$
\Phi_{2}(t)=\int_{a}^{b} G_{2}(x)\left[B_{n-1}^{*}\left(\frac{x-t}{b-a}\right)-B_{n-1}\left(\frac{x-a}{b-a}\right)\right] d x
$$

Theorem 17 Let $\mathrm{f}:[\mathrm{a}, \mathrm{b}] \rightarrow \mathbb{R}$ be such that $\mathrm{f}^{(\mathrm{n})}$ is absolutely continuous function for some $\mathrm{n} \geq 2$ with $(\cdot-\mathrm{a})(\mathrm{b}-\cdot)\left[\mathrm{f}^{(\mathrm{n}+1)}\right]^{2} \in \mathrm{L}[\mathrm{a}, \mathrm{b}]$ and let $\mathrm{g}$ be an integrable function on $[\mathrm{a}, \mathrm{b}]$. Let $\lambda=\int_{\mathrm{a}}^{\mathrm{b}} \mathrm{g}(\mathrm{t}) \mathrm{dt}$ and let the functions $\mathrm{G}_{2}, \mathrm{H}_{2}$ and $\Phi_{2}$ be defined by (12), (36) and (37) respectively. Then

(i)

$$
\begin{aligned}
& \int_{a}^{b} f(t) g(t) d t-\int_{b-\lambda}^{b} f(t) d t \\
& +\sum_{k=1}^{n} \frac{(b-a)^{k-2}}{(k-1) !}\left(\int_{a}^{b} G_{2}(x) B_{k-1}\left(\frac{x-a}{b-a}\right) d x\right)\left[f^{(k-1)}(b)-f^{(k-1)}(a)\right] \\
& -\frac{(b-a)^{n-3}\left[f^{(n-1)}(b)-f^{(n-1)}(a)\right]}{(n-1) !} \int_{a}^{b} H_{2}(t) d t=S_{n}^{3}(f ; a, b)
\end{aligned}
$$


where the remainder $S_{n}^{3}(f ; a, b)$ satisfies the estimation

$$
\left|S_{n}^{3}(f ; a, b)\right| \leq \frac{(b-a)^{n-\frac{3}{2}}}{\sqrt{2}(n-1) !}\left[T\left(H_{2}, H_{2}\right)\right]^{\frac{1}{2}}\left|\int_{a}^{b}(t-a)(b-t)\left[f^{(n+1)}(t)\right]^{2} d t\right|^{\frac{1}{2}} .
$$

(ii)

$$
\begin{aligned}
& \int_{a}^{b} f(t) g(t) d t-\int_{b-\lambda}^{b} f(t) d t \\
& +\sum_{k=1}^{n-1} \frac{(b-a)^{k-2}}{(k-1) !}\left(\int_{a}^{b} G_{2}(x) B_{k-1}\left(\frac{x-a}{b-a}\right) d x\right)\left[f^{(k-1)}(b)-f^{(k-1)}(a)\right] \\
& -\frac{(b-a)^{n-3}\left[f^{(n-1)}(b)-f^{(n-1)}(a)\right]}{(n-1) !} \int_{a}^{b} \Phi_{2}(t) d t=S_{n}^{4}(f ; a, b)
\end{aligned}
$$

where the remainder $S_{n}^{4}(f ; a, b)$ satisfies the estimation

$$
\left|S_{n}^{4}(f ; a, b)\right| \leq \frac{(b-a)^{n-\frac{3}{2}}}{\sqrt{2}(n-1) !}\left[T\left(\Phi_{2}, \Phi_{2}\right)\right]^{\frac{1}{2}}\left|\int_{a}^{b}(t-a)(b-t)\left[f^{(n+1)}(t)\right]^{2} d t\right|^{\frac{1}{2}} .
$$

Proof. Similar to the proof of Theorem 15.

The following Grüss type inequalities also hold.

Theorem 18 Let $\mathrm{f}:[\mathrm{a}, \mathrm{b}] \rightarrow \mathbb{R}$ be such that $\mathrm{f}^{(\mathrm{n})}(\mathrm{n} \geq 2)$ is absolutely continuous function and $\mathrm{f}^{(\mathrm{n}+1)} \geq 0$ on $[\mathrm{a}, \mathrm{b}]$. Let the function $\mathrm{H}_{1}$ be defined by (30). Then we have the representation (31) and the remainder $S_{\mathfrak{n}}^{1}(f ; a, b)$ satisfies the bound

$$
\left|S_{n}^{1}(f ; a, b)\right| \leq \frac{(b-a)^{n-1}}{(n-1) !}\left\|H_{1}^{\prime}\right\|_{\infty}\left\{\frac{f^{(n-1)}(b)+f^{(n-1)}(a)}{2}-\left[a, b ; f^{(n-2)}\right]\right\} .
$$

Proof. Applying Theorem 14 for $\mathrm{f} \rightarrow \mathrm{H}_{1}$ and $\mathrm{h} \rightarrow \mathrm{f}^{(\mathrm{n})}$ we obtain

$$
\begin{aligned}
& \left|\frac{1}{b-a} \int_{a}^{b} H_{1}(t) f^{(n)}(t) d t-\frac{1}{b-a} \int_{a}^{b} H_{1}(t) d t \cdot \frac{1}{b-a} \int_{a}^{b} f^{(n)}(t) d t\right| \\
& \leq \frac{1}{2(b-a)}\left\|H_{1}^{\prime}\right\|_{\infty} \int_{a}^{b}(t-a)(b-t) f^{(n+1)}(t) d t .
\end{aligned}
$$


Since

$$
\begin{aligned}
\int_{a}^{b}(t-a)(b-t) f^{(n+1)}(t) d t & =\int_{a}^{b}[2 t-(a+b)] f^{(n)}(t) d t \\
= & (b-a)\left[f^{(n-1)}(b)+f^{(n-1)}(a)\right]-2\left(f^{(n-2)}(b)-f^{(n-2)}(a)\right) .
\end{aligned}
$$

Using the representation (8) and the inequality (41) we deduce (40).

Theorem 19 Let $\mathrm{f}:[\mathrm{a}, \mathrm{b}] \rightarrow \mathbb{R}$ be such that $\mathrm{f}^{(\mathfrak{n})}(\mathrm{n} \geq 2)$ is absolutely continuous function and $\mathrm{f}^{(\mathrm{n}+1)} \geq 0$ on $[\mathrm{a}, \mathrm{b}]$. Let $\mathrm{H}_{1}, \Phi_{1}$ and $\Phi_{2}$ be defined by (30), (34) and (37), respectively. Then we have the representations (35), (38) and (39) where the remainders $S_{\mathfrak{n}}^{i}(f ; a, b), i=2,3,4$ satisfy the bounds

$$
\begin{aligned}
& \left|S_{n}^{2}(f ; a, b)\right| \leq \frac{(b-a)^{n-1}}{(n-1) !}\left\|\Phi_{1}^{\prime}\right\|_{\infty}\left\{\frac{f^{(n-1)}(b)+f^{(n-1)}(a)}{2}-\left[a, b ; f^{(n-2)}\right]\right\} \\
& \left|S_{n}^{3}(f ; a, b)\right| \leq \frac{(b-a)^{n-1}}{(n-1) !}\left\|H_{2}^{\prime}\right\|_{\infty}\left\{\frac{f^{(n-1)}(b)+f^{(n-1)}(a)}{2}-\left[a, b ; f^{(n-2)}\right]\right\}
\end{aligned}
$$

and

$$
\left|S_{n}^{4}(f ; a, b)\right| \leq \frac{(b-a)^{n-1}}{(n-1) !}\left\|\Phi_{2}^{\prime}\right\|_{\infty}\left\{\frac{f^{(n-1)}(b)+f^{(n-1)}(a)}{2}-\left[a, b ; f^{(n-2)}\right]\right\} .
$$

\section{Mean value theorems}

Motivated by inequalities (16), (18), (20) and (22), under the assumptions of Theorems 7 and 8 we define the following linear functionals:

$$
\begin{aligned}
& L_{1}(f)=\int_{a}^{a+\lambda} f(t) d t-\int_{a}^{b} f(t) g(t) d t \\
& +\sum_{k=1}^{n} \frac{(b-a)^{k-2}}{(k-1) !}\left(\int_{a}^{b} G_{1}(x) B_{k-1}\left(\frac{x-a}{b-a}\right) d x\right)\left[f^{(k-1)}(b)-f^{(k-1)}(a)\right] \\
& L_{2}(f)=\int_{a}^{a+\lambda} f(t) d t-\int_{a}^{b} f(t) g(t) d t \\
& +\sum_{k=1}^{n-1} \frac{(b-a)^{k-2}}{(k-1) !}\left(\int_{a}^{b} G_{1}(x) B_{k-1}\left(\frac{x-a}{b-a}\right) d x\right)\left[f^{(k-1)}(b)-f^{(k-1)}(a)\right]
\end{aligned}
$$




$$
\begin{aligned}
& L_{3}(f)=\int_{a}^{b} f(t) g(t) d t-\int_{b-\lambda}^{b} f(t) d t \\
& +\sum_{k=1}^{n} \frac{(b-a)^{k-2}}{(k-1) !}\left(\int_{a}^{b} G_{2}(x) B_{k-1}\left(\frac{x-a}{b-a}\right) d x\right)\left[f^{(k-1)}(b)-f^{(k-1)}(a)\right] \\
& L_{4}(f)=\int_{a}^{b} f(t) g(t) d t-\int_{b-\lambda}^{b} f(t) d t \\
& +\sum_{k=1}^{n-1} \frac{(b-a)^{k-2}}{(k-1) !}\left(\int_{a}^{b} G_{2}(x) B_{k-1}\left(\frac{x-a}{b-a}\right) d x\right)\left[f^{(k-1)}(b)-f^{(k-1)}(a)\right] .
\end{aligned}
$$

Remark 1 We have $L_{i}(f) \geq 0, i=1, \ldots, 4$ for all $n$-convex functions $f$.

Now, we give the Lagrange-type mean value theorem related to defined functionals.

Theorem 20 Let $\mathrm{f}:[\mathrm{a}, \mathrm{b}] \rightarrow \mathbb{R}$ be such that $\mathrm{f} \in \mathrm{C}^{\mathfrak{n}}[\mathrm{a}, \mathrm{b}]$. If the inequalities in $(15)(i=1),(17)(i=2),(19)(i=3)$ and $(21)(i=4)$ hold, then there exist $\xi_{i} \in[a, b]$ such that

$$
L_{i}(f)=f^{(n)}\left(\xi_{i}\right) L_{i}(\varphi), \quad i=1, \ldots, 4
$$

where $\varphi(x)=\frac{x^{n}}{n !}$ and $L_{i}, i=1, \ldots, 4$ are defined by $(42)-(45)$.

Proof. Let us denote

$$
m=\min _{x \in[a, b]} f^{(\mathfrak{n})}(x) \quad \text { and } \quad M=\max _{x \in[a, b]} f^{(\mathfrak{n})}(x) .
$$

For a given function $f \in C^{n}[a, b]$ we define the functions $F_{1}, F_{2}:[a, b] \rightarrow \mathbb{R}$ with

$$
F_{1}(x)=M \varphi(x)-f(x) \text { and } \quad F_{2}(x)=f(x)-m \varphi(x) .
$$

Now $F_{1}^{(n)}(x)=M-f^{(n)}(x) \geq 0$, so from Remark 1 we conclude $L_{i}\left(F_{1}\right) \geq 0, i=$ $1, \ldots, 4$ and then $L_{i}(f) \leq M \cdot L_{i}(\varphi)$. Similarly, from $F_{2}^{(n)}(x)=f^{(n)}(x)-m \geq 0$ we conclude $m \cdot L_{i}(\varphi) \leq L_{i}(f)$. Hence, $m \cdot L_{i}(\varphi) \leq L_{i}(f) \leq M \cdot L_{i}(\varphi), i=1, \ldots, 4$. If $\mathrm{L}_{\mathfrak{i}}(\varphi)=0$, then (46) holds for all $\xi_{\mathfrak{i}} \in[\mathrm{a}, \mathrm{b}]$. Otherwise,

$$
m \leq \frac{L_{i}(f)}{L_{i}(\varphi)} \leq M, \quad i=1, \ldots 4 .
$$


Since $\mathrm{f}^{(\mathfrak{n})}$ is continuous on $[\mathrm{a}, \mathrm{b}]$ there exist $\xi_{i} \in[a, b], i=1, \ldots, 4$ such that (46) holds and the proof is complete.

We continue with the Cauchy-type mean value theorem.

Theorem 21 Let $\mathrm{f}, \mathrm{F}:[\mathrm{a}, \mathrm{b}] \rightarrow \mathbb{R}$ be such that $\mathrm{f}, \mathrm{F} \in \mathrm{C}^{\mathfrak{n}}[\mathrm{a}, \mathrm{b}]$ and $\mathrm{F}^{(\mathrm{n})} \neq 0$. If the inequalities in $(15)(\mathfrak{i}=1),(17)(\mathfrak{i}=2),(19)(\mathfrak{i}=3)$ and $(21)(\mathfrak{i}=4)$ hold, then there exist $\xi_{i} \in[\mathrm{a}, \mathrm{b}]$ such that

$$
\frac{L_{i}(f)}{L_{i}(F)}=\frac{f^{(n)}(\xi)}{F^{(n)}(\xi)}, \quad i=1, \ldots, 4
$$

where $\mathrm{L}_{\mathfrak{i}}, \mathfrak{i}=1, \ldots, 4$ are defined by $(42)-(45)$.

Proof. We define functions $\phi_{i}(x)=f(x) L_{i}(F)-F(x) L_{i}(f), i=1, \ldots, 4$. According to Theorem 20 there exist $\xi_{i} \in[a, b]$ such that

$$
\mathrm{L}_{\mathfrak{i}}\left(\phi_{i}\right)=\phi_{i}^{(\mathrm{n})}\left(\xi_{i}\right) \mathrm{L}_{i}(\varphi), \quad i=1, \ldots, 4 .
$$

Since $L_{i}\left(\phi_{i}\right)=0$ it follows that $f^{(n)}\left(\xi_{i}\right) L_{i}(F)-F^{(n)}\left(\xi_{i}\right) L_{i}(f)=0$ and $(47)$ is proved.

\section{6 n-exponential convexity}

Let us begin by recalling some definitions and results related to $n-$ exponential convexity. For more details see e.g. [2], [6] and [9].

Definition 2 A function $\psi: \mathrm{I} \rightarrow \mathbb{R}$ is said to be $\mathrm{n}$-exponentially convex in the Jensen sense on I if

$$
\sum_{i, j=1}^{n} \xi_{i} \xi_{j} \psi\left(\frac{x_{i}+x_{j}}{2}\right) \geq 0,
$$

holds for all choices of $\xi_{i} \in \mathbb{R}$ and $x_{i} \in I, i=1, \ldots, n$.

A function $\psi: \mathrm{I} \rightarrow \mathbb{R}$ is said to be $\mathrm{n}$-exponentially convex if it is $\mathrm{n}$ exponentially convex in the Jensen sense and continuous on $\mathrm{I}$.

Remark 2 It is clear from the definition that 1-exponentially convex functions in the Jensen sense are in fact nonnegative functions. Also, $n$-exponentially convex functions in the Jensen sense are k-exponentially convex in the Jensen sense for every $k \in \mathbb{N}, k \leq n$. 
Definition 3 A function $\psi: \mathrm{I} \rightarrow \mathbb{R}$ is said to be exponentially convex in the Jensen sense on $\mathrm{I}$ if it is $\mathrm{n}$-exponentially convex in the Jensen sense for all $\mathrm{n} \in \mathbb{N}$.

A function $\psi: \mathrm{I} \rightarrow \mathbb{R}$ is said to be exponentially convex if it is exponentially convex in the Jensen sense and continuous.

Remark 3 It is known that $\psi: I \rightarrow \mathbb{R}$ is log-convex in the Jensen sense if and only if

$$
\alpha^{2} \psi(x)+2 \alpha \beta \psi\left(\frac{x+y}{2}\right)+\beta^{2} \psi(y) \geq 0,
$$

holds for every $\alpha, \beta \in \mathbb{R}$ and $x, y \in I$. It follows that a positive function is log-convex in the Jensen sense if and only if it is 2-exponentially convex in the Jensen sense.

A positive function is log-convex if and only if it is 2-exponentially convex.

Proposition 1 If $\mathrm{f}$ is a convex function on $\mathrm{I}$ and if $\mathrm{x}_{1} \leq \mathrm{y}_{1}, \mathrm{x}_{2} \leq \mathrm{y}_{2}, \mathrm{x}_{1} \neq$ $\mathrm{x}_{2}, \mathrm{y}_{1} \neq \mathrm{y}_{2}$, then the following inequality is valid

$$
\frac{f\left(x_{2}\right)-f\left(x_{1}\right)}{x_{2}-x_{1}} \leq \frac{f\left(y_{2}\right)-f\left(y_{1}\right)}{y_{2}-y_{1}} .
$$

If the function $\mathrm{f}$ is concave, the inequality is reversed.

We use defined functionals $\mathrm{L}_{i}, i=1, \ldots, 4$ to construct exponentially convex functions. An elegant method of producing $n-$ exponentially convex and exponentially convex functions is given in [9]. In the sequel the notion log denotes the natural logarithm function.

Theorem 22 Let $\Omega=\left\{f_{p}: p \in J\right\}$, where $J$ is an interval in $\mathbb{R}$, be a family of functions defined on an interval $\mathrm{I}$ in $\mathbb{R}$ such that the function $\mathrm{p} \mapsto$ $\left[\mathrm{x}_{0}, \ldots, \mathrm{x}_{\mathrm{m}} ; \mathrm{f}_{\mathrm{p}}\right]$ is $\mathrm{n}$-exponentially convex in the Jensen sense on $\mathrm{J}$ for every $(\mathrm{m}+1)$ mutually different points $\mathrm{x}_{0}, \ldots, \mathrm{x}_{\mathrm{m}} \in \mathrm{I}$. Let $\mathrm{L}_{\mathfrak{i}}, i=1, \ldots, 4$ be linear functionals defined by (42)-(45). Then $\mathrm{p} \mapsto \mathrm{L}_{\mathfrak{i}}\left(f_{\mathrm{p}}\right)$ is $\mathrm{n}$-exponentially convex function in the Jensen sense on $\mathrm{J}$.

If the function $\mathrm{p} \mapsto \mathrm{L}_{\mathfrak{i}}\left(\mathrm{f}_{\mathrm{p}}\right)$ is continuous on $\mathrm{J}$, then it is $\mathrm{n}$-exponentially convex on $\mathrm{J}$.

Proof. For $\xi_{j} \in \mathbb{R}$ and $p_{j} \in J, j=1, \ldots, n$, we define the function

$$
\Psi(x)=\sum_{j, k=1}^{n} \xi_{j} \xi_{k} \frac{f_{p_{j}+p_{k}}}{2}(x) .
$$


Using the assumption that the function $p \mapsto\left[x_{0}, \ldots, x_{m} ; f_{p}\right]$ is $n$-exponentially convex in the Jensen sense, we have

$$
\left[x_{0}, \ldots, x_{m}, \Psi\right]=\sum_{j, k=1}^{n} \xi_{j} \xi_{k}\left[x_{0}, \ldots, x_{m} ; \frac{f_{p_{j}+p_{k}}}{2}\right] \geq 0
$$

which in turn implies that $\Psi$ is a m-convex function on $\mathrm{J}$, so $\mathrm{L}_{\mathfrak{i}}(\Psi) \geq 0$, $i=1, \ldots, 4$. Hence

$$
\sum_{j, k=1}^{n} \xi_{j} \xi_{k} L_{i}\left(\frac{f_{p_{j}+p_{k}}}{2}\right) \geq 0 .
$$

We conclude that the function $p \mapsto L_{i}\left(f_{p}\right)$ is $n$-exponentially convex on $J$ in the Jensen sense.

If the function $p \mapsto L_{i}\left(f_{p}\right)$ is also continuous on $J$, then $p \mapsto L_{i}\left(f_{p}\right)$ is $n$ exponentially convex by definition.

As an immediate consequence of the above theorem we obtain the following corollary:

Corollary 1 Let $\Omega=\left\{f_{p}: p \in J\right\}$, where $J$ is an interval in $\mathbb{R}$, be a family of functions defined on an interval $\mathrm{I}$ in $\mathrm{R}$, such that the function $\mathrm{p} \mapsto$ $\left[\mathrm{x}_{0}, \ldots, \mathrm{x}_{\mathrm{m}} ; \mathrm{f}_{\mathrm{p}}\right]$ is exponentially convex in the Jensen sense on $\mathrm{J}$ for every $(\mathrm{m}+1)$ mutually different points $\mathrm{x}_{0}, \ldots, \mathrm{x}_{\mathrm{m}} \in \mathrm{I}$. Let $\mathrm{L}_{i}, \mathfrak{i}=1, \ldots, 4$, be linear functionals defined by (42)-(45). Then $\mathrm{p} \mapsto \mathrm{L}_{\mathfrak{i}}\left(\mathrm{f}_{\mathrm{p}}\right)$ is an exponentially convex function in the Jensen sense on $\mathrm{J}$. If the function $\mathrm{p} \mapsto \mathrm{L}_{\mathfrak{i}}\left(\mathrm{f}_{\mathrm{p}}\right)$ is continuous on $J$, then it is exponentially convex on $\mathrm{J}$.

Corollary 2 Let $\Omega=\left\{f_{p}: p \in J\right\}$, where $J$ is an interval in $\mathbb{R}$, be a family of functions defined on an interval $\mathrm{I}$ in $\mathbb{R}$, such that the function $\mathrm{p} \mapsto$ $\left[x_{0}, \ldots, x_{m} ; f_{p}\right]$ is 2-exponentially convex in the Jensen sense on $\mathrm{J}$ for every $(\mathrm{m}+1)$ mutually different points $x_{0}, \ldots, x_{\mathrm{m}} \in \mathrm{I}$. Let $\mathrm{L}_{\mathfrak{i}}, i=1, \ldots, 4$ be linear functionals defined by (42)-(45). Then the following statements hold:

(i) If the function $\mathrm{p} \mapsto \mathrm{L}_{\mathfrak{i}}\left(\mathrm{f}_{\mathrm{p}}\right)$ is continuous on $\mathrm{J}$, then it is 2-exponentially convex function on $\mathrm{J}$. If $\mathrm{p} \mapsto \mathrm{L}_{\mathfrak{i}}\left(\mathrm{f}_{\mathrm{p}}\right)$ is additionally strictly positive, then it is also log-convex on J. Furthermore, the following inequality holds true:

$$
\left[\mathrm{L}_{i}\left(f_{s}\right)\right]^{t-r} \leq\left[L_{i}\left(f_{r}\right)\right]^{t-s}\left[L_{i}\left(f_{t}\right)\right]^{s-r}, \quad i=1, \ldots, 4
$$

for every choice $\mathrm{r}, \mathrm{s}, \mathrm{t} \in \mathrm{J}$, such that $\mathrm{r}<\mathrm{s}<\mathrm{t}$. 
(ii) If the function $\mathrm{p} \mapsto \mathrm{L}_{\mathfrak{i}}\left(\mathrm{f}_{\mathrm{p}}\right)$ is strictly positive and differentiable on $J$, then for every $\mathrm{p}, \mathrm{q}, \mathrm{u}, v \in \mathrm{J}$, such that $\mathrm{p} \leq \mathrm{u}$ and $\mathrm{q} \leq \boldsymbol{v}$, we have

$$
\mu_{p, q}\left(L_{i}, \Omega\right) \leq \mu_{u, v}\left(L_{i}, \Omega\right),
$$

where

$$
\mu_{p, q}\left(L_{i}, \Omega\right)= \begin{cases}\left(\frac{L_{i}\left(f_{p}\right)}{L_{i}\left(f_{q}\right)}\right)^{\frac{1}{p-q}}, & p \neq q \\ \exp \left(\frac{\frac{d}{d p} L_{i}\left(f_{p}\right)}{L_{i}\left(f_{p}\right)}\right), & p=q\end{cases}
$$

for $\mathrm{f}_{\mathrm{p}}, \mathrm{f}_{\mathrm{q}} \in \Omega$.

\section{Proof.}

(i) This is an immediate consequence of Theorem 22 and Remark 3.

(ii) Since $p \mapsto L_{i}\left(f_{p}\right)$ is positive and continuous, by (i) we have that $p \mapsto$ $L_{i}\left(f_{p}\right)$ is log-convex on $J$, that is, the function $p \mapsto \log L_{i}\left(f_{p}\right)$ is convex on J. Applying Proposition 1 we get

$$
\frac{\log L_{i}\left(f_{p}\right)-\log L_{i}\left(f_{q}\right)}{p-q} \leq \frac{\log L_{i}\left(f_{u}\right)-\log L_{i}\left(f_{v}\right)}{u-v},
$$

for $p \leq u, q \leq v, p \neq q, u \neq v$. Hence, we conclude that

$$
\mu_{p, q}\left(L_{i}, \Omega\right) \leq \mu_{\mathfrak{u}, v}\left(L_{i}, \Omega\right) .
$$

Cases $p=q$ and $\mathfrak{u}=\boldsymbol{v}$ follow from (50) as limit cases.

Remark 4 Results from the above theorem and corollaries still hold when two of the points $x_{0}, \ldots, x_{m} \in I$ coincide, say $x_{1}=x_{0}$, for a family of differentiable functions $f_{p}$ such that the function $p \mapsto\left[x_{0}, \ldots, x_{m} ; f_{p}\right]$ is $n$-exponentially convex in the Jensen sense (exponentially convex in the Jensen sense, log-convex in the Jensen sense), and furthermore, they still hold when all $m+1$ points coincide for a family of $n$ differentiable functions with the same property. The proofs use (6) and suitable characterization of convexity. 


\section{Applications to Stolarsky type means}

In this section, we present some families of functions which fulfil the conditions of Theorem 22, Corollary 1, Corollary 2 and Remark 4. This enables us to construct a large families of functions which are exponentially convex. For a discussion related to this problem see [5].

Example 1 Let us consider a family of functions

$$
\Omega_{1}=\left\{f_{p}: \mathbb{R} \rightarrow \mathbb{R}: p \in \mathbb{R}\right\}
$$

defined by

$$
f_{p}(x)= \begin{cases}\frac{e^{p x}}{p^{n}}, & p \neq 0 \\ \frac{x^{n}}{n !}, & p=0\end{cases}
$$

Since $\frac{d^{n} f_{p}}{d x^{n}}(x)=e^{p x}>0$, the function $f_{p}$ is $n$-convex on $\mathbb{R}$ for every $p \in \mathbb{R}$ and $p \mapsto \frac{d^{n} f_{p}}{d x^{n}}(x)$ is exponentially convex by definition. Using analogous arguing as in the proof of Theorem 22 we also have that $p \mapsto\left[x_{0}, \ldots, x_{n} ; f_{p}\right]$ is exponentially convex (and so exponentially convex in the Jensen sense). Now, using Corollary 1 we conclude that $p \mapsto L_{i}\left(f_{p}\right), \mathfrak{i}=1, \ldots, 4$, are exponentially convex in the Jensen sense. It is easy to verify that this mapping is continuous (although the mapping $p \mapsto f_{p}$ is not continuous for $p=0$ ), so it is exponentially convex. For this family of functions, $\mu_{p, q}\left(L_{i}, \Omega_{1}\right), i=1, \ldots, 4$, from (49), becomes

$$
\mu_{p, q}\left(L_{i}, \Omega_{1}\right)= \begin{cases}\left(\frac{L_{i}\left(f_{p}\right)}{L_{i}\left(f_{q}\right)}\right)^{\frac{1}{p-q}}, & p \neq q, \\ \exp \left(\frac{L_{i}\left(i d \cdot f_{p}\right)}{L_{i}\left(f_{p}\right)}-\frac{n}{p}\right), & p=q \neq 0, \\ \exp \left(\frac{1}{n+1} \frac{L_{i}\left(i d \cdot f_{0}\right)}{L_{i}\left(f_{0}\right)}\right), & p=q=0,\end{cases}
$$

where $i d$ is the identity function. By Corollary $2 \mu_{p, q}\left(L_{i}, \Omega_{1}\right), i=1, \ldots, 4$ are monotonic functions in parameters $\mathrm{p}$ and $\mathrm{q}$.

Since

$$
\left(\frac{\frac{d^{n} f_{p}}{d x^{n}}}{\frac{d^{n} f_{q}}{d x^{n}}}\right)^{\frac{1}{p-q}}(\log x)=x,
$$

using Theorem 21 it follows that:

$$
M_{p, q}\left(L_{i}, \Omega_{1}\right)=\log \mu_{p, q}\left(L_{i}, \Omega_{1}\right), \quad i=1, \ldots, 4
$$

satisfy

$$
a \leq M_{p, q}\left(L_{i}, \Omega_{1}\right) \leq b, \quad i=1, \ldots, 4 .
$$

So, $M_{p, q}\left(L_{i}, \Omega_{1}\right), i=1, \ldots, 4$ are monotonic means. 
Example 2 Let us consider a family of functions

$$
\Omega_{2}=\left\{g_{p}:(0, \infty) \rightarrow \mathbb{R}: p \in \mathbb{R}\right\}
$$

defined by

$$
g_{p}(x)= \begin{cases}\frac{x^{p}}{p(p-1) \cdots(p-n+1)}, & p \notin\{0,1, \ldots, n-1\}, \\ \frac{x^{j} \log x}{(-1)^{n-1-j} j !(n-1-j) !}, & p=j \in\{0,1, \ldots, n-1\} .\end{cases}
$$

Since $\frac{d^{n} g_{p}}{d x^{n}}(x)=x^{p-n}>0$, the function $g_{p}$ is $n$-convex for $x>0$ and $p \mapsto$ $\frac{d^{n} g_{p}}{d x^{n}}(x)$ is exponentially convex by definition. Arguing as in Example 1 we get that the mappings $p \mapsto L_{\mathfrak{i}}\left(g_{p}\right), i=1, \ldots, 4$ are exponentially convex. Hence, for this family of functions $\mu_{p, q}\left(L_{i}, \Omega_{2}\right), i=1, \ldots, 4$, from (49), is equal to

$$
\mu_{p, q}\left(L_{i}, \Omega_{2}\right)=\left\{\begin{aligned}
\left(\frac{L_{i}\left(g_{p}\right)}{L_{i}\left(g_{q}\right)}\right)^{\frac{1}{p-q}}, \quad p \neq q, \\
\exp \left((-1)^{n-1}(n-1) ! \frac{L_{i}\left(g_{0} g_{p}\right)}{L_{i}\left(g_{p}\right)}+\sum_{k=0}^{n-1} \frac{1}{k-p}\right), \\
p=q \notin\{0,1, \ldots, n-1\}, \\
\exp \left((-1)^{n-1}(n-1) ! \frac{L_{i}\left(g_{0} g_{p}\right)}{2 L_{i}\left(g_{p}\right)}+\sum_{\substack{k=0 \\
k \neq p}}^{n-1} \frac{1}{k-p}\right), \\
p=q \in\{0,1, \ldots, n-1\} .
\end{aligned}\right.
$$

Again, using Theorem 21 we conclude that

$$
a \leq\left(\frac{L_{i}\left(g_{p}\right)}{L_{i}\left(g_{q}\right)}\right)^{\frac{1}{p-q}} \leq b, \quad i=1, \ldots, 4 .
$$

So, $\mu_{p, q}\left(L_{i}, \Omega_{2}\right), i=1, \ldots, 4$ are means and by (48) they are monotonic.

\section{Acknowledgements}

The research of Josip Pečarić and Ksenija Smoljak Kalamir has been fully supported by Croatian Science Foundation under the project 5435 and the research of Anamarija Perušić Pribanić has been fully supported by University of Rijeka under the project 13.05.1.1.02. 


\section{References}

[1] M. Abramowitz, I. A. Stegun (Eds), Handbook of mathematical functions with formulae, graphs and mathematical tables, National Bureau of Standards, Applied Math. Series 55, 4th printing, Washington, 1965.

[2] S. N. Bernstein, Sur les fonctions absolument monotones, Acta Math. 52 (1929), 1-66.

[3] P. Cerone, S. S. Dragomir, Some new Ostrowski-type bounds for the Čebyšev functional and applications, J. Math. Inequal., 8 (1) (2014), 159170.

[4] L J. Dedić, M. Matić, J. Pečarić, On generalizations of Ostrowski inequality via some Euler-type identities, Math. Inequal. Appl., 3 (3) (2000), $337-353$.

[5] W. Ehm, M. G. Genton, T. Gneiting, Stationary covariance associated with exponentially convex functions, Bernoulli, 9 (4) (2003), 607-615.

[6] J. Jakšetić, J. Pečarić, Exponential convexity method, J. Convex Anal., 20 (1) (2013), 181-197.

[7] V. I. Krylov, Approximate Calculation of Integrals, Macmillan, New YorkLondon, 1962.

[8] D. S. Mitrinović, The Steffensen inequality, Univ. Beograd. Publ. Elektrotehn. Fak. Ser. Mat. Fiz., 247-273 (1969), 1-14.

[9] J. Pečarić, J. Perić, Improvements of the Giaccardi and the Petrović inequality and related results, An. Univ. Craiova Ser. Mat. Inform. 39 (1) (2012), 65-75.

[10] J. E. Pečarić, F. Proschan, Y. L. Tong, Convex functions, partial orderings, and statistical applications, Mathematics in science and engineering 187, Academic Press, 1992.

[11] J. F. Steffensen, On certain inequalities between mean values and their application to actuarial problems, Skand. Aktuarietids., (1918), 82-97. 